\title{
Efeito antinociceptivo e antiinflamatório do extrato aquoso da entrecasca de Coutarea hexandra Schum. (Rubiaceae)
}

\author{
Josefina E.X. Lucena, Magna D. Bispo, Rogéria S. Nunes, Sócrates C.H.Cavalcanti, Flávia \\ Teixeira-Silva, Rosilene M. Marçal*, Ângelo R. Antoniolli
}

\author{
Departamento de Fisiologia, CCBS, Universidade Federal de Sergipe, Av. Marechal Rondon, s/n, Rosa Elze, \\ 49.001-970, São Cristóvão, Sergipe, Brasil
}

\begin{abstract}
RESUMO: No estado de Sergipe, o chá da entrecasca de Coutarea hexandra Shum. (Rubiaceae) é popularmente utilizado no combate à dor e à inflamação. Estes usos etnofarmacológicos vieram motivar os estudos sobre os efeitos antinociceptivo e antiinflamatório, bem como sobre a toxicidade aguda do extrato aquoso liofilizado da entrecasca de Coutarea hexandra. Doses orais do extrato aquoso significativamente reduziram as contorções abdominais induzidas por ácido acético, aumentaram o tempo de latência ao calor no teste da placa quente, reduziram o edema de pata induzido por carragenina e, na segunda fase do teste da formalina, também reduziram a resposta dos animais à formalina. $\mathrm{O}$ efeito detectado no teste da formalina não foi revertido por naloxona ou cafeína. Nos ensaios de toxicidade aguda, não foi observada a morte de nenhum animal até a dose de $5 \mathrm{~g} / \mathrm{kg}$. Em conclusão, o extrato aquoso da entrecasca de $C$. hexandra possui efeitos antiinflamatório e antinociceptivo e não apresenta toxicidade aguda em camundongos. $\mathrm{O}$ efeito antinociceptivo não está relacionado à ativação dos sistemas opióide e adenosina e, ao menos parcialmente, é decorrente da atuação do extrato aquoso em nível central.
\end{abstract}

Unitermos: Coutarea hexandra, Rubiaceae, quina-quina, atividade antiinflamatória, atividade analgésica.

\begin{abstract}
Antinociceptive and anti-inflammatory properties of Coutarea hexandra barks aqueous extract Schum. (Rubiaceae)." The aqueous extract of Coutarea hexandra Shum. (Rubiaceae) is extensively used on local folk medicine as anti-inflammatory and antinociceptive. In view of these facts, it was of our interest to evaluate the anti-inflammatory and antinociceptive activities. Its acute toxicity was also evaluated. The aqueous extract of Coutarea hexandra reduced acetic acid-induced writhing, increased the latency in the hot plate test, and reduced the second phase nociceptive response in the formalin test. Neither naloxone nor caffeine reversed aqueous extract of Coutarea hexandra effect in the second phase of the formalin test. The aqueous extract of Coutarea hexandra also reduced the rat paw edema induced by carrageenan. There was no animal death with doses up to $5 \mathrm{~g} / \mathrm{kg}$ in the acute toxicity assays. These results showed that aqueous extract of $C$. hexandra has low acute toxicity, as well as, anti-inflammatory and antinociceptive effects, substantiating its popular usage. The antinociceptive effect seems to involve a central component, although it is not directly related to the opioid and adenosine systems.
\end{abstract}

Keywords: Coutarea hexandra, Rubiaceae, quina-quina, antiinflammatory activity, analgesic activity.

\section{INTRODUÇÃO}

Coutarea hexandra Shum. (Rubiaceae) é uma planta arbórea amplamente distribuída no Brasil. No estado de Sergipe, esta planta é conhecida por quinaquina e o chá de sua entrecasca é popularmente utilizado como diurético, como abortivo e no combate à dor e à inflamação.

Os estudos mais recentes sobre plantas do gênero Coutarea abordam principalmente questões pertinentes à distribuição, filogenia e ecologia (McDowell et al., 2003; Ivizi; Araújo, 1997). Estudos fitoquímicos revelaram a presença de flavonóides (Reher et al., 1983; Iinuma et al., 1987; Dellemonache et al., 1989) e cumarinas (Aquino et al., 1988; D'agostino et al., 1989a; D'agostino et al., 1989b; D'agostino et al., 1990; Dellemonache et al., 1983; Dellemonache et al., 1984; Dellemonache et al., 1990) em extratos de C. hexandra. Algumas das cumarinas isoladas da $C$. hexandra também têm sido sintetizadas (Iinuma et al., 1987; Dellemonache et al., 1985).

Atividade antimalárica in vitro (Noster; Kraus, 1990), hipoglicemiante (Barbosa-Filho et al., 2005) bem como hemólise e rabdomiólise em seres humanos (Roca, 2003) têm sido detectadas para Coutarea latiflora. A 
indicação popular de efeito abortivo para a casca de $C$. hexandra foi avaliada em ratas tendo se observado efeito antifertilizante após tratamento com a fração acetato de etila desta casca enquanto a fração hexânica, embora não tenha apresentado efeito anti-fertilizante, interferiu no crescimento fetal e aumentou a mortalidade intra-uterina (Almeida et al., 1990). Reabsorção fetal foi observada na presença do extrato etanólico da casca de Coutarea hexandra (Rao et al., 1988) e atividade antiinflamatória (Falcão et al., 2005).

Apesar do extenso uso etnomedicinal da Coutarea hexandra como analgésico e antiinflamatório, não foram encontrados na literatura estudos farmacológicos que investigassem estes efeitos. Em vista destes fatos, os objetivos do presente trabalho foram avaliar os efeitos antinociceptivo e anti-edematogênico do extrato aquoso da entrecasca de $C$. hexandra, tendo sido avaliada também a toxicidade aguda.

\section{MATERIAL E MÉTODOS}

\section{Material botânico}

As entrecascas de Coutarea hexandra foram coletadas no povoado de "Capim Grosso" na cidade de Canindé do São Francisco $\left(09^{\circ} 38^{\prime} \mathrm{S}, 37^{\circ} 47^{\prime} \mathrm{W}\right)$, estado de Sergipe, Brasil. A identidade botânica da planta foi confirmada pela bióloga Gilvane Viana Souza e um espécime coletado encontra-se depositado no Herbário da Universidade Federal de Sergipe (número de voucher 007259; Universidade Federal de Sergipe, CCBS, Departamento de Biologia, São Cristovão, Sergipe, 49100-000, Brasil).

\section{Preparo do extrato aquoso}

As entrecascas de $C$. hexandra foram secas em estufa $\left(40^{\circ} \mathrm{C}\right.$, Marconi MA 037) durante $48 \mathrm{~h}$ e trituradas em moinho de facas até se obter o pó. A este pó (200 g) adicionou-se água destilada $\left(1: 10 \mathrm{w} / \mathrm{v} ; 75^{\circ} \mathrm{C}\right)$ e se manteve esta mistura em infusão durante 30 minutos. $\mathrm{O}$ extrato aquoso assim obtido foi filtrado sob vácuo $\mathrm{e}$ liofilizado (VirTis, Benchtop) rendendo um pó branco $(16,0 \mathrm{~g} ; 8 \%$ ), o qual foi conservado em dessecador até o momento do uso.

\section{Preparo das drogas e diluição do extrato aquoso}

As drogas utilizadas foram diluídas de forma a se obter um volume de injeção de $0,1 \mathrm{~mL}$ para $10 \mathrm{~g}$ de peso do animal. Ácido acético (Merck), hidrocloreto de morfina (Sigma), formalina $1 \%$ (Baker), hidrocloreto de naloxona (Sigma), cafeína (Sigma) e carragenina (Sigma) foram dissolvidos em água. Indometacina (Sigma) foi diluída em água/ $\mathrm{NaOH} 0.1 \mathrm{~N}(\mathrm{pH}=8)$. $\mathrm{O}$ extrato aquoso liofilizado foi diluído em água no dia do experimento tendo sido preparadas três concentrações diferentes de solução de forma a se obter três doses diferentes mantendo-se o volume administrado de $0,1 \mathrm{~mL} / 10 \mathrm{~g}$ de animal.

\section{Animais}

Foram utilizados camundongos Swiss (20$35 \mathrm{~g})$ e ratos Wistar (150-260 g), machos e fêmeas. Os animais foram mantidos em caixas plásticas com comida e água à vontade. Os animais submetidos à administração oral de extrato aquoso ou de drogas foram mantidos em jejum (apenas de ração) durante doze horas. Todos os experimentos foram realizados de acordo com as normas vigentes para trabalho com animais de laboratório e com as normas éticas para investigações de dor experimental em animais acordados (Zimmerman, 1983) e os protocolos utilizados foram aprovados pelo Comitê de Ética em Pesquisa com Animais desta instituição em 25 de maio de 2005.

Toxicidade aguda (Lorke, 1983)

Três grupos de camundongos $(\mathrm{n}=5)$ receberam doses crescentes do extrato aquoso de $C$. hexandra $(1,3 \mathrm{e}$ $5 \mathrm{~g} / \mathrm{kg}$; p.o.). Um grupo $(\mathrm{n}=5)$ recebeu apenas o veículo (água destilada). O índice de mortalidade foi observado após 48 horas.

Teste das contorções abdominais induzidas por ácido acético (Koster; Anderson; De Beer, 1959)

Este teste foi realizado em seis grupos de camundongos $(\mathrm{n}=09)$. Todos os animais receberam ácido acético a $0,6 \%(0,1 \mathrm{~mL} / 10 \mathrm{~g}$; i.p.) e, dez minutos após a administração de ácido acético, as contorções abdominais foram contadas, durante 20 minutos, para todos os grupos de animais. O extrato aquoso de C. hexandra $(100,200 \mathrm{e}$ $400 \mathrm{mg} / \mathrm{kg}$; p.o.) foi administrado a três grupos de animais uma hora antes da administração do agente nociceptivo. Um grupo de animais recebeu apenas água destilada (p.o., grupo controle). As drogas padrão, morfina (2,5 $\mathrm{mg} / \mathrm{kg}$, i.p.) e indometacina (10 $\mathrm{mg} / \mathrm{kg}$, p.o.), foram administradas 45 e 60 minutos, respectivamente, antes da administração do ácido acético.

\section{Teste da placa quente (Ankier, 1974)}

Camundongos $(\mathrm{n}=09)$ foram colocados sobre uma placa de alumínio aquecida a temperatura fixa $\left(55 \pm 0,5^{\circ} \mathrm{C}\right)$ e o tempo de latência ao calor foi avaliado utilizando como parâmetro o tempo que o animal levou para retirar uma pata traseira da placa quente e lambêla. O tempo de corte utilizado foi de trinta segundos. Os experimentos foram iniciados 60 minutos após a administração do extrato aquoso $(100,200$ e $400 \mathrm{mg} /$ $\mathrm{kg}$, p.o.). A droga padrão morfina (10 mg/kg, i.p.) foi administrada 45 minutos antes da medida do tempo de latência. 
Tabela 1. Efeito do extrato aquoso de C. hexandra no teste das contorções induzidas por ácido acético $(0,6 \%)$.

\begin{tabular}{llll}
\hline TRATAMENTO & DOSE (mg/kg) & $\begin{array}{l}\text { No. DE CONTORÇÕES } \\
\text { ABDOMINAIS (MEEPM) }\end{array}$ & $\begin{array}{l}\text { DEDÇÃO DAS } \\
\text { CONTORÇÕES } \\
\text { ABDOMINAIS }\end{array}$ \\
\hline Controle (salina, p.o.) & - & $31,89 \pm 2,69$ & - \\
Indometacina (p.o.) & 10 & $3,33 \pm 0,72^{* * *}$ & 89 \\
Morfina (i.p.) & 2,5 & $3,78 \pm 0,95^{* * *}$ & 88 \\
Extrato Aquoso & 100 & $22,3 \pm 2,18$ & 30 \\
(p.o.) & 200 & $14,89 \pm 2,36$ & 53 \\
\hline
\end{tabular}

Cada valor representa a média e erro padrão da média de nove camundongos. As diferenças estatísticas foram determinadas por Kruskal-Wallis seguido de Dunn, ${ }^{*} \mathrm{p}<0,05 ;{ }^{*} \mathrm{p}<0,01 ;{ }^{* * *} \mathrm{p}<0,001$ (versus controle). As porcentagens de redução do número de contorções abdominais foram calculadas em relação ao grupo controle.

Tabela 2. Efeito do extrato aquoso de $C$. hexandra no teste da placa quente $\left(55 \pm 0,5^{\circ} \mathrm{C}\right)$.

\begin{tabular}{llll}
\hline TRATAMENTO & DOSE (mg/kg) & $\begin{array}{l}\text { TEMPO (s) DE LATENCIA AO } \\
\text { CALOR (M } \pm \text { EPM) }\end{array}$ & $\begin{array}{l}\text { \% DE AUMENTO DO } \\
\text { TEMPO DE LATENCIA }\end{array}$ \\
\hline Controle (salina, p.o.) & - & $13,12 \pm 0,85$ & - \\
Morfina (i.p.) & 5 & $30,00 \pm 0,0^{* * *}$ & 128 \\
& 100 & $22,78 \pm 2,31^{*}$ & 74 \\
Extrato Aquoso & 200 & $23,78 \pm 2,02^{*}$ & 81 \\
(p.o.) & 400 & $24,32 \pm 2,15^{*}$ & 85 \\
\hline
\end{tabular}

Cada valor representa a média e erro padrão da média de nove camundongos. As diferenças estatísticas foram determinadas por Kruskal-Wallis seguido de Dunn, ${ }^{*} \mathrm{p}<0,05 ; * * \mathrm{p}<0,01 ; * * * \mathrm{p}<0,001$ (versus controle). As porcentagens de aumento do tempo de latência ao calor foram calculadas em relação ao grupo controle.

Tabela 3. Efeito do extrato aquoso de $C$. hexandra no teste da formalina ( $1 \%)$.

\begin{tabular}{|c|c|c|c|c|c|}
\hline \multirow[b]{2}{*}{ TRATAMENTO } & \multirow[b]{2}{*}{$\begin{array}{c}\text { DOSE } \\
(\mathrm{mg} / \mathrm{kg})\end{array}$} & \multicolumn{2}{|c|}{ 1A. FASE } & \multicolumn{2}{|c|}{ 2A. FASE } \\
\hline & & TEMPO (s) & $\begin{array}{c}\text { \% DE } \\
\text { REDUÇÃO DO } \\
\text { TEMPO }\end{array}$ & TEMPO (s) & $\begin{array}{c}\text { \% DE } \\
\text { REDUÇÃO DO } \\
\text { TEMPO }\end{array}$ \\
\hline Controle (salina) & - & $50,22 \pm 3,90$ & - & $28,00 \pm 2,81$ & - \\
\hline Morfina (i.p.) & 7,5 & $8,89 \pm 2,08^{* * *}$ & 82 & $0,11 \pm 0,10^{* * *}$ & 100 \\
\hline $\begin{array}{l}\text { Morfina (i.p.) + Naloxona } \\
\text { (i.p.) }\end{array}$ & $7,5+5,0$ & $38,52 \pm 4,33$ & 23 & $18,50 \pm 3,82$ & 34 \\
\hline & 100 & $39,44 \pm 6,62$ & 21 & $1,11 \pm 0,69^{* *}$ & 96 \\
\hline Extrato aquoso (p.o.) & $\begin{array}{l}200 \\
400\end{array}$ & $\begin{array}{l}46,33 \pm 3,86 \\
43,22 \pm 4,19\end{array}$ & $\begin{array}{l}8 \\
14\end{array}$ & $\begin{array}{l}3,44 \pm 1,18^{*} \\
3,00 \pm 1,91^{* *}\end{array}$ & $\begin{array}{l}88 \\
89\end{array}$ \\
\hline $\begin{array}{l}\text { Extrato aquoso (p.o.) }+ \\
\text { naloxona (i.p.) }\end{array}$ & $100+5$ & $37,13 \pm 5,43$ & 26 & $0,00 \pm 0,00 * * *$ & 100 \\
\hline $\begin{array}{l}\text { Extrato aquoso (p.o.) + } \\
\text { cafeína (i.p.) }\end{array}$ & $100+20$ & $38,25 \pm 4,47$ & 24 & $2,88 \pm 1,12 * * *$ & 90 \\
\hline
\end{tabular}

Cada valor representa a média e erro padrão da média $(n=09)$ do tempo que os animais passaram lanbendo a pata traseira. As diferenças estatísticas foram determinadas por Kruskal-Wallis seguido de Dunn, ${ }^{*} \mathrm{p}<0,05 ; * * \mathrm{p}<0,01 ;{ }^{* * *} \mathrm{p}<0,001$ (versus controle). As porcentagens de redução do tempo de reação do animal foram calculadas em relação ao grupo controle salina.

\section{Teste do edema de pata induzido por carragenina} (Winter; Risley; Nuss, 1962)

O efeito anti-edematogênco foi avaliado através do teste do edema de pata $(n=08)$ induzido por carragenina $(1 \%)$. A droga padrão indometacina (10 $\mathrm{mg} / \mathrm{kg}$, p.o.) e o extrato aquoso de C. hexandra (100, 200, e $400 \mathrm{mg} / \mathrm{kg}$, p.o.) foram administrados uma hora antes da injeção intraplantar do agente flogístico. $\mathrm{O}$ grupo controle recebeu igual volume de água destilada (p.o.) uma hora antes da administração de carragenina. $\mathrm{O}$ volume da pata foi medido imediatamente após a administração da carragenina (tempo zero) e também $1,2,3$ e 4 horas pós-carragenina. As medidas foram realizadas através do método do deslocamento da solução aquosa de detergente neutro $\left(0,3 \mathrm{~g} \mathrm{NaCl}, 0,7 \mathrm{~L} \mathrm{H}_{2} \mathrm{O}, 2 \mathrm{~mL}\right.$ de detergente) utilizando-se um pletismômetro (modelo 7150, Ugo Basile). 
Tabela 4. Efeito do extrato aquoso de C. hexandra no teste do edema de pata induzido por carragenina (1\%).

\begin{tabular}{|c|c|c|c|c|c|c|c|c|c|}
\hline \multirow[t]{2}{*}{ TRATAMENTO } & \multirow{2}{*}{$\begin{array}{c}\text { DOSE } \\
(\mathrm{mg} / \mathrm{kg})\end{array}$} & \multicolumn{8}{|c|}{$\begin{array}{c}\text { VOLUME (mL) DA PATA } \\
\text { M } \pm \text { EPM }\end{array}$} \\
\hline & & $1 \mathrm{~h}$ & $\%$ & $2 \mathrm{~h}$ & $\%$ & $3 \mathrm{~h}$ & $\%$ & $4 \mathrm{~h}$ & $\%$ \\
\hline \multirow{2}{*}{$\begin{array}{l}\text { Controle } \\
\text { (salina, p.o.) } \\
\text { Indometacina (i.p.) }\end{array}$} & - & $1,33 \pm 0,07$ & - & $1,60 \pm 1,4$ & - & $1,69 \pm 0,12$ & - & $1,70 \pm 0,12$ & - \\
\hline & 10 & $0,82 \pm 0,03^{* * *}$ & 38 & $0,88 \pm 0,03^{* * *}$ & 45 & $0,97 \pm 0,06^{* * *}$ & 43 & $1,00 \pm 0,07^{* * *}$ & 41 \\
\hline \multirow{3}{*}{$\begin{array}{l}\text { Extrato Aquoso } \\
\text { (p.o.) }\end{array}$} & 100 & $1,07 \pm 0,05^{*}$ & 20 & $1,22 \pm 0,06^{* *}$ & 24 & $1,31 \pm 0,03^{* *}$ & 22 & $1,36 \pm 0,06$ & 20 \\
\hline & 200 & $1,22 \pm 0,06$ & 9 & $1,40 \pm 0,08$ & 12 & $1,55 \pm 0,06$ & 8 & $1,48 \pm 0,09$ & 13 \\
\hline & 400 & $1,26 \pm 0,06$ & 5 & $1,44 \pm 0,06$ & 10 & $1,48 \pm 0,06$ & 12 & $1,42 \pm 0,06$ & 16 \\
\hline
\end{tabular}

Cada valor representa a média e erro padrão da média de oito camundongos. As diferenças estatísticas foram determinadas por ANOVA seguido de Tukey, ${ }^{*} \mathrm{p}<0,05 ;{ }^{*} \mathrm{p}<0,01 ;{ }^{* *} \mathrm{p}<0,001$ (versus controle). As porcentagens de redução do volume da pata foram calculadas em relação ao grupo controle.

Teste da formalina (Hunskaar; Hole, 1987)

Após administração intraplantar de formalina $(0,02 \mathrm{~mL}$ de solução de formalina a $1 \%)$ o tempo que cada animal passou lambendo a pata traseira foi cronometrado em duas fases sendo a primeira de 0-5 minutos e a segunda de 20-30 minutos após a administração de formalina. O extrato aquoso de $C$. hexandra (100, 200 e $400 \mathrm{mg} / \mathrm{kg}$, p.o.) foi administrado 60 minutos antes da injeção de formalina. $\mathrm{O}$ grupo controle recebeu apenas veículo (água, p.o.) uma hora antes da administração de formalina e outro grupo de animal recebeu a droga padrão morfina $(7,5 \mathrm{mg} / \mathrm{kg}$, i.p) 45 minutos antes da formalina. Com o objetivo de verificar a participação do sistema opióide no efeito do extrato foi realizada a coadministração do extrato aquoso de C. hexandra $(100 \mathrm{mg} /$ $\mathrm{kg}$, p.o., 60 minutos antes da formalina) e do antagonista opióide naloxona $(5 \mathrm{mg} / \mathrm{kg}$, i.p., 45 minutos antes da formalina). Um grupo controle adicional foi realizado pela co-administração de morfina e naloxona $(7,5 \mathrm{mg} / \mathrm{kg}$, i.p. e $5 \mathrm{mg} / \mathrm{kg}$, i.p., respectivamente, 45 minutos antes da formalina). Com o objetivo de verificar a participação do sistema adenosina no efeito do extrato realizou-se a co-administração de cafeína $(20 \mathrm{mg} / \mathrm{kg}$, i.p., 45 minutos antes da formalina) e do extrato aquoso de $C$. hexandra (100 mg/kg, p.o., 60 minutos antes da formalina). Todos os grupos foram compostos por oito animais.

\section{Análise estatística}

Os resultados foram expressos através da média e erro padrão da média. Os resultados do teste do edema de pata induzido por carragenina foram submetidos à análise de variância ANOVA seguida pelo pós-teste de Tukey. Os outros testes farmacológicos foram analisados através da análise de variância não-paramétrica Kruskal-Wallis seguida pelo pós-teste de Dunn, quando apropriado. Um nível de significância de $5 \%$ foi utilizado em todas as análises. As porcentagens de redução do edema de pata, da reação à formalina ou do número de contorções foram calculadas através da formula 100 - (100 x Vt/Vc), onde $\mathrm{Vt}$ e Vc representam a média do volume da pata ou da resposta do animal para o grupo tratado e controle, respectivamente. As porcentagens de aumento do tempo de latência ao calor foram calculadas pela fórmula (100 $\mathrm{X} \mathrm{Xc/Xt)} \mathrm{-} \mathrm{100,} \mathrm{onde} \mathrm{Xc} \mathrm{e} \mathrm{Xt} \mathrm{representam} \mathrm{as} \mathrm{médias} \mathrm{do}$ tempo de latência para os grupos controle e tratados, respectivamente.

\section{RESULTADOS}

No teste das contorções abdominais induzidas por ácido acético $(0,6 \%)$, o extrato aquoso de $C$. hexandra $(400 \mathrm{mg} / \mathrm{kg})$, reduziu significativamente $(\mathrm{p}<0,01)$ as contorções abdominais induzidas por ácido acético. As porcentagens de redução das contorções abdominais foram de 30, 53 e $78 \%$ para as doses 100 , 200 e $400 \mathrm{mg} / \mathrm{kg}$ do extrato aquoso de C. hexandra, respectivamente. As drogas padrão, morfina $(2,5 \mathrm{mg} / \mathrm{kg}$, i.p.) e indometacina $(10 \mathrm{mg} / \mathrm{kg}$, p.o.), também reduziram de forma significativa as contorções abdominais induzidas por ácido acético $(\mathrm{p}<0,001$ para ambas as drogas). Estes resultados encontram-se na tabela 1 .

No teste da placa quente (tabela 2), o extrato aquoso de C. hexandra, nas doses de 100, 200 e 400 mg/ $\mathrm{kg}$, reduziu significativamente o tempo de latência ao calor $(\mathrm{p}<0,05$ para todas as doses). As porcentagens de redução do tempo de latência ao calor foram de 74,81 e $85 \%$, para as doses 100, 200 e $400 \mathrm{mg} / \mathrm{kg}$, respectivamente.

Na segunda fase do teste da formalina $(1 \%)$, tanto o extrato aquoso de $C$. hexandra, nas doses de 100, 200 e $400 \mathrm{mg} / \mathrm{kg}(\mathrm{p}<0,01, \mathrm{p}<0.05, \mathrm{p}<0.01$, respectivamente), quanto a droga padrão morfina $(7,5 \mathrm{mg} / \mathrm{kg}, \mathrm{p}<0,001)$ reduziram de maneira significativa o tempo de resposta dos animais à formalina $(1 \%)$. Na primeira fase deste teste, no entanto, apenas a droga padrão (morfina; 7,5 $\mathrm{mg} / \mathrm{kg}$ ) foi eficaz em reduzir a resposta dos animais à formalina $(p<0,001)$. Neste teste, nem a cafeína (20 $\mathrm{mg} / \mathrm{kg}, \mathrm{p}<0,001)$ nem a naloxona $(5 \mathrm{mg} / \mathrm{kg}, \mathrm{p}<0,001)$ reverteram o efeito do extrato aquoso de $C$. hexandra $(100 \mathrm{mg} / \mathrm{kg})$. Estes resultados bem como as porcentagens 
de redução encontram-se na tabela 3.

No teste do edema de pata induzido por carragenina ( $1 \%$ ), o extrato aquoso de Coutarea hexandra, na dose de $100 \mathrm{mg} / \mathrm{kg}$, reduziu de forma significativa o edema de pata uma $(\mathrm{p}<0,05)$, duas $(\mathrm{p} \leq 0,01)$ e três horas $(p \leq 0,01)$ após a administração da carragenina. Neste teste, a droga padrão indometacina reduziu o edema de pata após uma e até quatro horas pós-carragenina (controle positivo, $\mathrm{p}<0,001)$. As porcentagens de redução do edema de pata pelo extrato aquoso de Coutarea hexandra foram de $20,24,22$ e $20 \%$ após uma, duas, três e quatro horas da administração de carragenina, respectivamente (tabela 4).

Nos ensaios de toxicidade aguda, não foi possível determinar a $\mathrm{DL}_{50}$ da planta posto que nenhum animal morreu mesmo utilizando-se dose de $5 \mathrm{~g} / \mathrm{kg}$.

\section{DISCUSSÃO}

O chá da entrecasca de Coutarea hexandra é utilizado popularmente no combate à dor e à inflamação. No presente trabalho, esta indicação etnofarmacológica foi avaliada através de três diferentes modelos de estudo para nocicepção (teste da placa quente, da formalina e contorções abdominais induzidas por ácido acético) e tambémdeummodelobaseadoemestímuloedematogênico (teste do edema de pata induzido por carragenina). Cabe aqui ressaltar que, para realizar estas avaliações, foram utilizados o extrato aquoso da entrecasca da Coutarea hexandra e a via de administração oral, mantendo-se desta forma os parâmetros do estudo científico o mais próximos possível da indicação etnomedicinal da planta.

Os resultados obtidos no presente estudo indicaram que o extrato aquoso de $C$. hexandra apresenta efeito antinociceptivo, o qual pode ser detectado tanto em modelos de estudo baseados em estímulo nociceptivo químico, como a formalina e o ácido acético, quanto em estímulo térmico (placa quente). Em outras palavras, a redução significativa das contorções abdominais induzidas por ácido acético $(0,6 \%$, tabela 1$)$, os aumentos significativos (tabela 2) do tempo de latência ao calor no teste da placa quente $\left(55 \pm 0,5^{\circ} \mathrm{C}\right)$ e a redução significativa (tabela 3) da resposta dos animais à formalina (1\%) vieram confirmar que o extrato aquoso de $C$. hexandra apresenta efeito antinociceptivo estando de acordo com o efeito analgésico sugerido pelo uso popular.

$\mathrm{O}$ teste da placa quente $\left(55 \pm 0,5^{\circ} \mathrm{C}\right.$, tabela 2$)$, é um teste seletivo para detecção de substâncias analgésicas com efeito central (Ankier, 1974) e os resultados obtidos neste teste, indicaram que, ao menos em parte, o efeito antinociceptivo do extrato aquoso de C. hexandra é decorrente da atuação deste extrato em nível central.

No teste da formalina ( $1 \%$ ), o padrão de eficácia detectado, após o tratamento com o extrato aquoso de C. hexandra (tabela 3), foi semelhante ao observado para drogas antiinflamatórias, analgésicas ou não, como indometacina, naproxeno, dexametasona e hidrocortisona
(Hunskaar; Hole, 1987). Estes resultados suportam a idéia de que o extrato aquoso de C. hexandra possa atuar também como antiinflamatório.

Adicionalmente, o efeito analgésico do extrato aquoso de $C$. hexandra parece ser decorrente de mecanismos que não dependem da ativação do sistema opióide uma vez o extrato aquoso foi eficaz apenas na segunda fase do teste da formalina ( $1 \%$; tabela 3$)$, enquanto agonistas opióides reduzem a resposta dos animais à formalina em ambas as fases deste teste (Hunskaar; Hole, 1987). Também o antagonista opióide naloxona $(5 \mathrm{mg} / \mathrm{kg})$ não foi capaz de reverter o efeito do extrato de $C$. hexandra vindo este fato a reiterar a idéia de que o extrato não atue via sistema opióide.

O sistema adenosina também tem sido implicado no efeito antinociceptivo (Daval; Nehlig; Nicholas, 1991). Porém, no teste da formalina, cafeína $(20 \mathrm{mg} / \mathrm{kg}$, tabela 3) não reverteu o efeito do extrato aquoso de $C$. hexandra e estes resultados sugerem que o efeito do extrato não envolva também a ativação do sistema adenosina.

No teste do edema de pata induzido por carragenina (1\%), o extrato aquoso de C. hexandra apresentou efeito anti-edematogênico (tabela 4). O teste do edema de pata induzido por carragenina (1\%) tem sido extensamente utilizado como modelo de estudo de inflamação (Di Rosa; Girold; Willoughby, 1971) bem como para a avaliação de substâncias antiinflamatórias (Winter; Risley; Nuss, 1962) sendo que o desenvolvimento deste edema envolve inclusive a participação de diferentes mediadores do processo inflamatório (Di Rosa; Girold; Willoughby, 1971). Levando-se em conta estes fatos, a eficácia do extrato aquoso de C. hexandra neste teste vem reiterar a idéia de o referido extrato aquoso atue como antiinflamatótio. No entanto, a droga-padrão indometacina $(10 \mathrm{mg} / \mathrm{kg})$ apresentou maior eficácia do que o extrato aquoso de C. hexandra $(100 \mathrm{mg} / \mathrm{kg}$, tabela 4) em reduzir o edema de pata por carragenina $(1 \%)$. Esta diferença pode estar relacionada à heterogeneidade de propriedades farmacocinéticas ou farmacodinâmicas (McGaw et al., 1997).

Cabe aqui ressaltar que os efeitos analgésico e antiinflamatório têm sido detectados para a entrecasca de outras plantas da família Rubiaceae como Uncaria tomentosa e Mytragina ciliata. Porém, o perfil da resposta farmacológica destas plantas apresenta aspectos diversos do observado no presente trabalho para $C$. hexandra. A entrecasca da Uncaria tomentosa apresenta eficácia em ambas as fases do teste da formalina e a entrecasca da Mytragina ciliata é eficaz em reduzir o edema de pata induzido por carragenina de 30 minutos a duas após a administração do agente flogístico (Jürgensen et al., 2005; Dongmo et al., 2003).

Segundo Lorke (1983), substâncias cuja $\mathrm{DL}_{50}$ ultrapassa $5 \mathrm{~g} / \mathrm{kg}$ podem ser consideradas atóxicas. O extrato aquoso de C. hexandra (p.o.) não causou a morte de camundongos com doses de até $5 \mathrm{~g} / \mathrm{kg}$, podendo, portanto ser considerado atóxico. 
Em conclusão, o extrato aquoso da Coutarea hexandra, nas doses administradas, possui efeito antiinflamatórioeantinociceptivo.Oefeitoantinociceptivo do extrato aquoso não está relacionado a ativação dos sistemas opióide e adenosina e, ao menos em parte, é devido a atuação em nível central.

\section{REFERÊNCIAS}

Almeida FRC, Rao VSN, Gadelha MGT, Matos FJA 1990. Estudo sobre a atividade antifertilizante de Coutarea Hexandra Schum. em ratos. Rev Bras Farm 71: 6971.

Ankier SI 1974. New hot plate test to quantify antinociceptive and narcotic-antagonist activities. Eur J Pharmacol 27,1-4.

Aquino R, Dagostino M, Desimone F, Pizza C 1988. Plant metabolites - 10.4-arylcoumarin glycosides from Coutera hexandra. Phytochemistry 27: 1827-1830.

Barbosa-Filho JM, Vasconcelos THC, Alencar AA, Batista LM, Oliveira RAG, Guedes DN, Falcão, HS, Moura MD, Diniz MFFM, Modesto-Filho J 2005. Plants and their active constituents from South, Central, and North América with hypoglycemic activity. Rev Bras Farmacogn 15: 392-413.

D'agostino M, Defeo V, Desimone F, Vincieri FF, Pizza C 1989. Isolation of 8-hydroxi-5,7,3',4'-tetramethoxy-4phenylcoumarin from Coutarea hexandra. Planta Med 6: 578-578.

D'agostino M, Defeo V, Desimone F, Pizza C 1989a. 4Arylcoumarin from Coutarea hexandra. Phytochemistry 28: 1773-1774.

D'agostino M, Desimone F, Dini A, Pizza C 1990. Isolation of $\quad 8,3$ '-dihydroxy-5,7,4'-trimethoxy-4phenylcoumarin from Coutarea hexandra. J Nat Prod 53: 161-162.

Davai JL, Nehlig A, Nicolas F 1991. Physiological and pharmacological properties of adenosine: therapeutic implications. Life Sci 49: 1435-1453.

Dellemonache G, Botta B, Neto AS, Delima RA 1983. 4- Arylcoumarin from Coutarea hexandra. Phytochemistry 22: 1657-1658.

Dellemonache G, Botta B, Delima RA 1984. A 4-arylcoumarin from Coutarea hexandra. Phytochemistry 23: 18131813.

Dellemonache G, Botta B, Dellemonache F, Botta M. 1985. Synthesis of 4-arylcoumarin from Coutarea hexandra. Phytochemistry 24: 1355-1357.

Dellemonache G, Botta B, Vinciguerra V, Gacsbaitz E 1989. A new neoflavonoid from Coutarea hexandra. Heterocycles 29: 355-357.

Dellemonache G, Botta B, Vinciguerra V, Pinheiro RM 1990. Constituents of Coutarea hexandra. 6. 4- Arylcoumarins from Coutarea hexandra Phytochemistry 29: 3984-3986.

Di Rosa M, Giroud JP, Willoughby DA 1971. Studies on the mediators of the acute inflammatory response induced in rats in different sites by carrageenan and turpentine. J Pathol 104: 15-29.

Falção HS, Lima IO, Santos VL, Dantas HF, Diniz MFFM, Barbosa-Filho JM, Batista LM 2005. Review of the plants with anti-inflammatory activity studied in Brazil. Rev Bras Farmacogn 15: 381-391.

Husnkaar S, Hole K 1987. The formalin test in mice: dissociation between inflammatory and non-inflamamatory pain. Pain 30: 103-119.

Iinuma M, Tanaka T, Hamada K, Mizuno M, Asai F, Reher G, Kraus L 1987. Revised structure of neoflavone in Coutarea hexandra. Phytochemistry 26: 30963097.

Ivizi L, Araujo GM 1997 Phenology of 14 tree species of a deciduous seasonal forest in Uberlandia, MG, central Brazil. Arquiv Biol Tecnol 40: 883-892.

Jurgensen S, DaiBo S, Angers P, Santos ARS, Ribeiro-doValle RM 2005. Involvement of 5-HT2 receptors in the antinociceptive effect of Uncaria tomentosa. Pharmacol Biochem Be 81: 466-477.

Koster R, Anderson M, De Beer EJ 1959. Acetic acid for analgesic screening Fed Proc 18: 412-416.

Lorke DA 1983. New approach to practical acute toxicity testing. Arch Toxicol 54: 275-287.

McDowell T, Volovsek M, Manos P 2003. Biogeography of exostema (Rubiaceae) in the Caribbean region in light of molecular phylogenetic analyses Syst Bot 28: 431-441.

McGaw LJ, Jager AK, van Staden J 1997. Prostaglandin synthesis inhibitory activity in Zulu, Xhosa and Sotho medicinal plants Phytother Res 11: 113-117

Noster S, Kraus L 1990. In vitro antimalarial activity of Coutarea latiflora and exostema-caribbean extracts on Plasmodium-falciparum. Planta Med 56: 63-65.

Rao VSN, Menezes AMS, Gadelha MGT 1988. Fitoterapia 59: 17-20. Apud Almeida FRC, Rao VSN, Gadelha MGT, Matos FJA 1990. Estudo sobre a atividade antifertilizante de Coutarea hexandra Schum. em ratos. Rev Bras Farm 71: 69-71.

Reher G, Kraus L, Sinnwell V, Konig WA 1983. A neoflavonoid from Coutarea hexandra (Rubiaceae). Phytochemistry 22: 1524-1525.

Roca B 2003. Rhabdomyolysis and hemolysis after use of Coutarea latiflora. Am J Med 115: 677-677.

Winter CA, Risley EA, Nuss GW 1962. Carrageenin-induced edema in hind paw of the rat as an assay for antiiflammatory drugs Proc Soc Exp Biol Med 111: 544547.

Zimmermann M 1983 Ethical guidelines for investigations of experimental pain in conscious animals Pain 16:109-110. 